\title{
Avian pox in a turkey vulture (Cathartes aura) from northern Chile
}

\author{
Mauricio Mora-Carreño ${ }^{\mathrm{a}, \mathrm{b}^{*}}$, Carlos Guerra-Correa ${ }^{\mathrm{a}, \mathrm{c}}$, \\ Manuel Moronid, Enrique Paredes ${ }^{d}$
}

\begin{abstract}
A debilitated turkey vulture (Cathartes aura), showing prominent nodular masses in its head, was found in Antofagasta, Chile. Histopathological examination revealed the presence of epidermal hyperplasia and hypertrophy with typical eosinophilic intracytoplasmatic inclusion bodies in epithelial cells. Accordingly, a diagnosis of avian pox was established, corresponding to the first known occurrence of the disease in the southern hemisphere.

Keywords: Avian pox, Cathartes aura, turkey vulture, Chile.
\end{abstract}

Avian pox infection is a common viral disease affecting domestic and wild birds worldwide, including 278 species of 20 different orders (van Riper and Forrester 2007). The infection is caused by a double-stranded DNA virus of the Poxviridae family, consisting of very large, oval or brick-shaped enveloped viruses (Bolte et al 1999, Shearn-Bochsler et al 2008). The clinical manifestations of this relatively slow-developing disease occur mainly in two different types: the cutaneous form, characterised by the development of proliferative lesions on the skin of the comb, wattle and other unfeathered areas, and the diphteric form, in which slightly elevated white opaque nodules develop in the mucous membrane of the mouth and upper respiratory tract (Tripathy 1993). Most avipoxviruses tend to be species-specific, however, some have been reported to cross genus, family and order barriers (Gyuranecz et al 2013). Virus transmission is density dependant, occurring primarily by direct contact with infected birds, and also by exposure to air-borne particles, by insects such as mosquitoes and mites acting as mechanic vectors, or by contact with contaminated elements like food, water or surfaces (van Ripper and Forrester 2007, Shearn-Bochsler et al 2008).

The turkey vulture (Cathartes aura) is the most widespread of new world vultures, occurring from Canada to Argentina and Chile, and is one of three scavenger species in the genus Cathartes of the family Cathartidae (Houston 1994). An adult turkey vulture, debilitated and unable to fly, was captured on the 11 of October 2012 by governmental

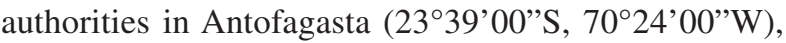
located in the Antofagasta Region, northern Chile. The

Accepted: 06.09.2018

${ }^{a}$ Centro de Rescate y Rehabilitación de Fauna Silvestre, Universidad de Antofagasta, Antofagasta, Chile.

bFundación Parque Científico Tecnológico de la Región de Antofagasta, Universidad Católica del Norte, Antofagasta, Chile.

${ }^{c}$ Centro Regional de Estudios y Educación Ambiental, Universidad de Antofagasta, Antofagasta, Chile.

dInstituto de Patología Animal, Facultad de Ciencias Veterinarias, Universidad Austral de Chile, Valdivia, Chile.

*Corresponding author: M Mora-Carreño; Av. Angamos 0610, Antofagasta, Chile; m.mora.mv@ hotmail.com bird was handed over to the Wildlife Centre of Rescue and Rehabilitation, Universidad de Antofagasta, for clinical examination. During the initial inspection the bird seemed depressed with poor reaction to external stimulation as well as low body condition. The head of the turkey vulture had one prominent nodular mass (of approximately $4 \times 3 \times 3 \mathrm{~cm}$ ) attached to its maxillary bill, right in front of its nostrils (figure 1A). A second, smaller nodular mass $(1 \times 1 \times 1 \mathrm{~cm})$ was observed on the left side of its head, right behind the left nostril. Both nodular masses were dark-brown coloured with a firm and wrinkled consistency. While the bigger nodular mass was deeply attached to the maxillary bill, the smaller nodule was only superficially attached and easily removed afterwards, revealing an infected purulent tissue underneath. A treatment consisting of fluid therapy, antibiotics and vitamins was implemented, however its condition continued to deteriorate, especially in the context of its anorexia. After eleven days at the centre the bird died showing signs of ataxia, which was attributed to a prolonged hypoglycaemia due to anorexia.

A necropsy examination was performed some hours after the bird died. Beyond the previously described lesions on the head, no other macroscopic findings were observed during the procedure. The whole head and samples of different tissues were preserved in 10\% buffered formalin and sent to the Pathology Institute of the Universidad Austral de Chile, in Valdivia, Chile, for histological examination with haematoxylin and eosin (H\&E) stain. These tissues collected during the necropsy were analysed, including samples of the epithelial tissue found in the nodular masses of the head. The latter samples were observed with a light microscope, revealing hypertrophy and hyperplasia with ballooning degeneration of epithelial cells and the presence of typical eosinophilic intracytoplasmatic inclusion bodies in the nodular mass (figure 1B). Accordingly, a diagnosis of avian pox was made, as these findings are considered pathognomonic for this viral disease, providing the basis for the diagnosis (Smits et al 2005, van Riper and Forrester 2007).

Later, in December 2017, a Chilean birdwatcher in Arica (located some $575 \mathrm{~km}$ north of Antofagasta) photographed a 


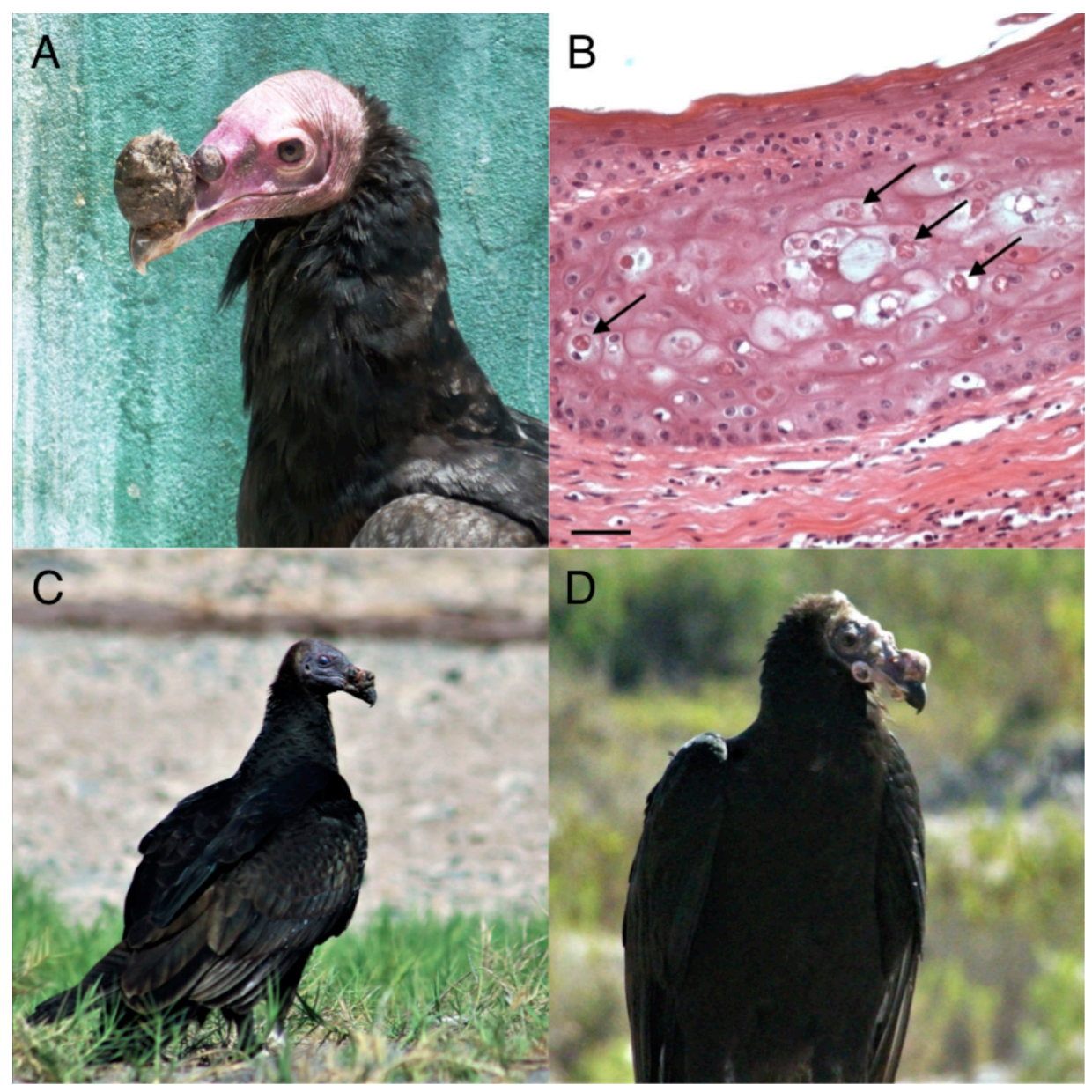

Figure 1. A) Lateral view of turkey vulture showing two nodular masses in its maxillary bill due to poxvirus infection. Photograph taken by Mauricio Mora-Carreño on October 2012. B) Histological section of the maxillary nodular mass, showing hyperplasia, hypertrophy and ballooning degeneration of epithelial cells with eosinophilic intracytoplasmatic inclusion bodies (arrows). H\&E stain 400X. Bar, $20 \mu \mathrm{m}$. Photograph taken by Manuel Moroni on March 2013. C) Juvenile turkey vulture observed at the Wetlands of the Lluta River Mouth, in the Arica and Parinacota Region, Chile. A nodular mass could be observed attached to its maxillary bill, in front of its right nostril. Photograph taken by birdwatcher Fidel Lara on December 2017. D) Juvenile turkey vulture observed at the Wetlands of the Lluta River Mouth, in the Arica and Parinacota Region, Chile. Multiple nodular masses could be observed attached to its face. Photograph taken by birdwatcher Fidel Lara on February 2018.

group of around ten turkey vultures of which three juveniles presented macroscopic lesions suspicious of avian pox in their head and legs (figure 1C). These birds were resting at the Wetlands of the Lluta River Mouth $\left(18^{\circ} 24^{\prime} 57^{\prime \prime} \mathrm{S}\right.$, $70^{\circ} 19^{\prime} 20^{\prime \prime} \mathrm{W}$ ) located in the Arica and Parinacota Region, the northernmost region of Chile. Three months later, in February 2018, the same photographer spotted another turkey vulture with macroscopic lesions suspicious of the cutaneous form of avian pox (figure 1D). None of these individuals with lesions on their heads and legs were captured; therefore a diagnosis could not be established.

To our knowledge, our case of avian pox in a turkey vulture with presence of intracytoplasmatic inclusion bodies in its nodular masses represents the first occurrence of the disease in the southern hemisphere and the third case reported worldwide. Previously, the diphteric form of avian pox was observed in three nestling turkey vultures in Florida (USA) in 1978, which died within six days of being removed from their nests. The diagnosis was made based on the presence of typical pox lesions and inclusion bodies in the cytoplasm of chorioallantoic membranes of inoculated chicken eggs (Forrester and Spalding 2003). Subsequently in 2008, a hatchling turkey vulture was diagnosed with the cutaneous form of avian pox in Venezuela (Gomez et al 2014). The individual was caught for a wing-tagging procedure, during which small cutaneous lesions were observed in the head of the bird. Before releasing the turkey vulture, samples for histopathology were taken from the nodules and later confirmed to be avian pox by the presence of intracytoplasmatic inclusion bodies observed with a light microscope (Gomez et al 2014). 
The conservation implications of the presence of avian pox in a turkey vulture and the suspicion of other cases in northern Chile need appropriate attention. Although the majority of avian pox cases for wild birds show mild and self-limited infections (van Ripper and Forrester 2007), a wide range of pathogenicity is seen among different avian poxviruses and hosts (Smits et al 2005) and severe infections and outbreaks have been documented (Bolte et al 1999, van der Werf 2001). The turkey vultures mentioned in this report are most probably Cathartes aura jota, which occurs from Colombia to Patagonia and is the only subspecies reported in northern Chile (FergusonLees and Christie 2001, Jaramillo 2013). Considering that some populations of this subspecies are described to be migrant, the possibility of infected $C$. $a$. jota individuals transmitting the disease to other subspecies like C. aura meridionalis, which is described from southern Canada to central South America, might represent a plausible risk of infection (Ferguson-Lees and Christie 2001). Thus, the possibility of the disease reaching more distant areas across the species range distribution should not be discarded in advance.

Additionally, and even though turkey vultures in northern Chile are not classified as Endangered, other sympatric species of birds might be eventually affected, given the capacity of the virus to affect different hosts, especially of the same family or order (Gyuranecz et al 2013, Henriques et al 2016). A particular cause of concern could be the habitat co-existence between turkey vultures and Andean Condor (Vultur gryphus) in northern Chile, the only other member of the Cathartidae family previously reported with avian pox infection (Kim et al 2003). Although a previous study conducted in Chile to evaluate the presence of avian pox antibodies in Andean Condor showed negative results (Toro et al 1997), the appearance of a poxvirus outbreak in a sympatric and closely related species like the turkey vulture might imply a potential source of infection for this iconic species.

The causes, transmission source, and potential impact of the emergence of avian poxvirus here reported in a turkey vulture in northern Chile are not yet known. The lifestyle of wild bird populations allows the spread and infection of avian pox among different subpopulations and also to novel species through species introductions, habitat change and bird migration (Gyuranesc et al 2013). The latter aspect is especially important for turkey vulture, considered the most migratory of all avian scavengers (Hedlin et al 2013). We encourage Chilean entities like SAG (Agricultural and Livestock Service) and CONAF (National Forestry Corporation), in collaboration with wildlife centres and research institutions, to increase the monitoring and health assessments of wild bird populations, especially regarding new world vulture populations of northern Chile. More research regarding migrant habits of $C$. $a$. jota and other subspecies is also encouraged, as well as increasing the monitoring of viral diseases along the range distribution of the species. Increasing the knowledge of avian pox and other infectious diseases affecting scavenging birds of prey might help to prevent the appearance of undesirable outbreaks of infectious diseases with unknown sanitary and conservation implications for native bird species.

\section{ACKNOWLEDGEMENTS}

We thank Dr. Rosanna Mattiello and Dr. Donald J. Forrester for their expert advice and contribution to orientate our case. We appreciate the help provided by Dr. Claudio Verdugo and his technical collaborators for their contribution analysing the tissue samples in the laboratory. We thank Dr. Álvaro Jaramillo for sharing his recognised knowledge of ornithology with us. We are also grateful to Fidel Lara, Chilean birdwatcher, for kindly providing us with the pictures of turkey vultures from Arica, Chile. Finally, we appreciate the improvements in English usage made by Bron Gwyther.

\section{REFERENCES}

Bolte A, Meurer J, Kaleta E. 1999. Avian host spectrum of avipoxviruses. Avian Pathol 28, 415-432.

Ferguson-Lees J, Christie D. 2001. Raptors of the world. Houghton Mifflin Harcourt, Boston, USA.

Forrester J, Spalding G. 2003. Parasites and diseases of wild birds in Florida. University Press of Florida, Gainesville, USA.

Gomez O, López R, Naveda-Rodriguez A. 2014. Avian Pox in Turkey Vulture (Cathartes aura). Vulture News 66, 42-48.

Gyuranecz M, Foster J, Dán Á, Ip H, Egstad K, et al. 2013. Worldwide phylogenetic relationship of avian poxviruses. J Virol 87, 4938-4951.

Hedlin E, Houston C, McLoughlin P, Bechard M, Stoffel M, et al. 2013. Winter ranges of migratory Turkey Vultures in Venezuela. J Raptor Res 47, 145-152.

Henriques A, Fagulha T, Duarte M, Ramos F, Barros S, et al. 2016. Avian poxvirus infection in a Flamingo (Phoenicopterus ruber) of the Lisbon Zoo. J Zoo Wildlife Med 47, 161-174.

Houston D. 1994. Family Cathartidae (New World Vultures). In: Del Hoyo J, Elliot A, Sargatal J (eds). Handbook of the Birds of the World. Lynx Editions, Barcelona, Spain, Pp 24-41.

Jaramillo A. 2013. Aves de Chile. Lynx Ediciones, Barcelona, España.

Kim T, Schnitzlein W, McAloose D, Pessier A, Tripathy D. 2003. Characterization of an avianpox virus isolated from an Andean condor (Vultur gryphus). Vet Microbiol 96, 237-246.

Shearn-Bochsler V, Green D, Converse K, Docherty D, Thiel T, et al. 2008. Cutaneous and diphtheritic avian poxvirus infection in a nestling Southern Giant Petrel (Macronectes giganteus) from Antarctica. Polar Biol 31, 569-573.

Smits J, Tella J, Carrete M, Serrano D, López G. 2005. An epizootic of avian pox in endemic short-toed larks (Calandrella rufescens) and Berthelot's pipits (Anthus berthelotti) in the Canary Islands, Spain. Vet Pathol 42, 59-65.

Toro H, Pavez E, Gough R, Montes G, Kaleta E. 1997. Serum chemistry and antibody status to some avian pathogens of free-living and captive condors (Vultur gryphus) of central Chile. Avian Pathol 26, 339-345.

Tripathy D. 1993. Avipox viruses. In: McFerran J, McNulty M (eds). Virus infections of birds. Elsevier, New York, USA, Pp 5-15.

van der Werf E. 2001. Distribution and potential impacts of avian poxlike lesions in elepaio at Hakalau Forest National Wildlife Refuge. Stud Avian Biol 22, 247-253.

van Riper C, Forrester D. 2007. Avian pox. In: Thomas N, Hunter D, Atkinson T (eds). Infectious Diseases of Wild Birds. Blackwell Publishing, Oxford, UK, Pp 131-176. 
